\title{
Há Rota de Fuga para Alguns, ou Somos Todos Vulneráveis? A Radicalidade da Crise e a Educação Ambiental
}

\section{Is There an Escape Route for Some or Are We All Vulnerable? The Crisis Radicality and Environmental Education}

\author{
Mauro Guimarães ${ }^{1}$;Pablo Ángel Meira Cartea ${ }^{2}$
}

1 Doutor em Ciências Sociais pela Universidade Federal Rural do Rio de Janeiro (2003), Professor pesquisador do quadro permanente do Programa de Pós Graduação em Educação da Universidade Federal Rural do Rio de Janeiro e Professor da Graduação de Geografia e Pedagogia. Líder do Grupo de Estudos e Pesquisa em Educação Ambiental, Diversidade e Sustentabilidade (GEPEADS). Coordenador do GT 22 de Educação Ambiental na ANPEd (2013-2015), Rio de Janeiro, Brasil - email guimamauro@ hotmail.com / ORCID 0000-0002-4158-313X

2 Profesor Titular de Educación Ambiental (EA) en la Universidad de Santiago de Compostela. Miembro del Grupo de Investigación en Pedagogía Social y Educación Ambiental (SEPA). Su investigación se centra en estudio de las bases teóricas de la EA, el diseño y la evaluación de políticas públicas de EA, en las representaciones sociales del cambio climático y en la educación y comunicación para responder a la emergencia climática. Premio María Barbeito de Investigación Pedagógica (2009). Director del Proyecto Resclima. ORCID: 0000-0003-0194-7477

\section{Palavras-chave:}

Crise Socioambiental 1. Educação Ambiental 2.

Formação de Educadores 3.

\section{Keywords:}

Socioenvironmental Crisis 1. Environmental Education 2. Educator Training 3.
RESUMO: Diante da degradação socioambiental crescente no mundo, apresentamos a mudança climática como um reflexo de uma crise que é civilizatória. A gravidade extrema deste problema demonstra a necessidade da urgência no enfrentamento pela Educação Ambiental em participar do processo de transformação radical do modo de vida da sociedade hegemônica atual. Para esta radicalidade necessitamos da formação de educadores ambientais transformados e transformadores.
ABSTRACT: Faced to the growing world's socioenvironmental degradation, we're presenting climate change as a reflex of a crisis that is civilizing. The extreme gravity of this problem demonstrates the need for urgency by Environmental Education to facing and participate to the process of radical transformation of the current hegemonic society's way of life. For this radicality we need transformed and transforming environmental educators training. 


\section{ENSINO, SAÚDE E AMBIENTE}

\section{CRISE SOCIOAMBIENTAL, PARADIGMÁTICA E CIVILIZATÓRIA?}

Para pensarmos a Educação Ambiental, seus educadores e os caminhos a seguir, o contexto histórico de uma crise sem precedentes na história da humanidade torna-se estruturante do devir.

Edgar Morin afirma, em sua vasta obra, que fomos construindo ao longo da história uma forma de compreender o mundo que referenciou o modo de viver da sociedade moderna. Forma de compreender estruturada por "paradigmas disjuntivos" (Morin, 1999) que trazem como algumas consequências a fragmentação do conhecimento da realidade, assim como estrutura uma visão reducionista que simplifica a complexidade do real. Entre as muitas dimensões que poderíamos exemplificar nessa discussão trazida por Morin e por tantos outros, vamos explorar um pouco a dimensão cartesiana que consolidou a Ciência Moderna.

O método cartesiano, que validou a forma científica de produzir conhecimento na modernidade, tem como uma de suas primeiras etapas na sistematização da produção do conhecimento, a delimitação do objeto de estudo como forma de aproximação com a realidade. Este esforço analítico, de se aproximar para conhecer uma parte delimitada de uma realidade mais ampla (totalidade), induziu a um direcionamento focado do olhar da modernidade, especificando e especializando a compreensão sobre essa parte e suas particularidades. Esse processo gerou a produção de áreas do conhecimento e sua disciplinarização, por uma abordagem de especialização do conhecimento. Sem desconsiderar os grandes avanços na ciência e produção de tecnologia pelo cartesianismo mecanicista, a busca pelo conhecimento de realidades cada vez mais complexas na contemporaneidade, em suas multidimensionalidades, tem encontrado importantes limitações pela fragmentação e reducionismo na compreensão dessas realidades complexas (totalidades), como é a questão da atual crise socioambiental.

Essa perspectiva disjuntiva paradigmática construiu uma estrutura de pensamento individual e coletivo que tem como ponto de partida uma visão social de mundo particularista 
(focada na parte), que gera todo um modo de estar no mundo, e que se torna basilar a centralidade no indivíduo para se entender a sociedade. O indivíduo como sua parte fundante - a célula máter. Assim, se entende a sociedade (totalidade) como resultado da soma destas partes (indivíduos). Seguindo essa mesma estrutura de pensamento, a propriedade da parte (particular) sobrepõe à dimensão coletiva do bem comum, tornando-o prioritário. É, portanto, essa perspectiva estruturante que hegemonizou o modo de vida da sociedade moderna, em que o sistema político e econômico do capitalismo se globalizou. Junta-se a essa perspectiva disjuntiva fragmentária a visão da separação, da segregação e da exclusão, que se interpõe na relação entre as partes a partir de relações assimétricas de poder, em que a dominação e exploração de uma parte sobre outra, se constitui num padrão organizativo das relações da modernidade; seja nas relações de classe, gênero, étnicas, coloniais e entre as nações nortesul. Dessa mesma forma, a relação entre sociedade e natureza consolida-se em uma perspectiva antropocêntrica.

Como nos diz Morin em suas reflexões, os paradigmas são referenciais historicamente construtores de um modo de conceber a realidade. Essas referências entranhadas nas estruturas de pensamento dos indivíduos e da sociedade constituem um modo dominante de pensar e fazer, o que consolida assim um modo de vida constituído por esses paradigmas. Referências que vão se repetindo e que passam a ser tão normal o assim fazer, que nem mais pensamos nelas - fazemos. Desta feita, referências se introjetam em nosso inconsciente, promovendo em nosso viver cotidiano, na maior parte do tempo, práticas não refletidas. Práticas essas que, baseadas nessa forma "normal" e dominante de fazer, tendem a reforçar inconscientemente esse modo de vida, no caso da modernidade, disjuntivo, particularista, individualista, que resultam em posturas individuais e coletivas de dominação, exploração e exclusão. Isso reforça e reproduz um modelo de organização social, em um modo de agir e pensar que se faz presente no inconsciente coletivo, que reflete e é reflexo do modo de produção e consumo que historicamente se faz hegemônico. Entretanto, é esse modelo de sociedade e suas relações socioambientais que têm levado ao colapso as condições de sustentabilidade da vida, em que as mudanças climáticas e suas drásticas consequências, são as evidências mais contundentes de que vivemos uma crise em uma escala planetária. Crise essa provocada pela forma hegemônica de pensar e viver; de um modo de produzir e consumir que se globalizou em sua economia exploratória e de degradações socioambientais que mostram agora seus claros limites planetários para se reproduzir. É, portanto, uma crise de um modelo civilizatório, de seu padrão de desenvolvimento e de seus paradigmas.

Portanto, continuar pensando e vivendo referenciado por esse paradigma disjuntivo da modernidade é alimentar e intensificar a crise em que estamos mergulhados. Buscar soluções para essa crise reforçando o fazer disjuntivo é propor que, como disse Lowy (2009), alguém 
que afunda na areia movediça saia dela puxando o seu próprio cabelo. Focar numa parte do problema para solucioná-lo, descontextualizando essa parte de uma realidade maior que ilustra o que estamos chamando de postura disjuntiva particularista, é o que vem sendo feito predominantemente referenciado por essa forma de pensar e fazer disjuntivo, simplificador e reducionista. Quando temos um "ataque de pragas" na agricultura, busca-se cientificamente o domínio de identificar a espécie e o veneno mortífero para eliminá-la. Joga-se o veneno na parte (a praga) que está atrapalhando essa produção específica, só que essa parte está inserida em um todo maior (natureza) que intoxicará, com o veneno contaminante, outros seres vivos em relação nesta teia. É nessa perspectiva simplificadora e reduzida de se aproximar da realidade, focado na parte, que aqui exemplificamos didaticamente, que se estrutura o nosso modo de viver e de nos relacionarmos com o outro (indivíduo e natureza). Sempre com a tendência de reproduzir um padrão de relação com o outro, dominando-o para explorá-lo em favor da parte dominadora. Eis o padrão de relação dualista e dicotômico da modernidade: dominação e exploração de um sobre o outro e que está presente nas relações coloniais de opressor e oprimido; entre nações do Norte e do Sul; entre classes sociais; nas relações étnicas, de gênero, nas relações entre sociedade humana e natureza; como já dissemos. O paradigma disjuntivo da modernidade que estrutura esse modo de vida, ao focar sua forma de olhar o mundo e buscar sua compreensão e ação na parte, na particularidade, no privado, tende, muitas das vezes inconscientemente, mas de outras ideologicamente, a priorizar a parte sobre o todo, o individual sobre o coletivo, o privado sobre o público, a competição sobre a colaboração e o egoísmo sobre a solidariedade.

Somos seres vivos individualmente muito frágeis, comparados a outras espécies muito maiores, mais fortes, mais ágeis e biologicamente adaptáveis. Como conseguimos ao longo da história da evolução das espécies chegarmos até aqui? O escritor israelense Yuval Noah Harari (2017) nos diz que certamente a inteligência, como praticamente todos responderíamos, mas não somente. Segundo ele, somos seres sociais em que a importância da ação colaborativa no coletivo foi também fundamental. A solidariedade está no cerne de nossa sobrevivência e essa parece que foi sendo posta como algo secundário no modo de vida da modernidade. A competição entre as partes, em que o interesse particular, da propriedade particular, de uma parte prevalecer sobre a outra, de um indivíduo poder mais que outro, da prevalência do individual sobre o coletivo, gesta-se com isso um campo fértil para se estabelecer o padrão relacional de dominação e exploração, que veio estruturando o modo de organização social da modernidade e seu modo de produção e consumo capitalista. A competição, o indivíduo, a propriedade particular, a dominação e exploração, tornam-se referências estruturantes da organização social desse modo de vida da modernidade e das relações que se estabelecem entre as partes viventes desse modelo civilizatório. Nesta 
perspectiva, o neoliberalismo não é apenas uma "estrutura ideológica" ou uma "forma de organização social e / ou econômica"; indo além, o neoliberalismo foi afirmado e consolidado por meio da colonização de subjetividades, principalmente por promover a competitividade entre os indivíduos e a primazia de interesses particulares sobre o bem comum. Como afirma Laval e Dardot (2013), “o que é (...) é sobre a construção de uma nova subjetividade, o que chamamos de sujeição contábil e financeira, que não é senão a forma mais bem-sucedida de sujeição capitalista. É, de fato, produzir uma relação do sujeito individual consigo mesma que seja homóloga à relação do capital consigo mesmo: uma relação, precisamente, do sujeito consigo como "capital humano" que deve aumentar indefinidamente, isto é, um valor que temos que aumentar cada vez mais. "Uma das grandes dificuldades da mudança que requer a transição para sociedades mais equitativas e sustentáveis e que é necessário rebelar-se, e não contra o sistema, contra si mesmo. Ou seja, questionando nossa identidade neoliberal.

A exacerbação por esse modo de pensar e viver do poderoso indivíduo humano (alguns), tem levado ao extremismo do individualismo, do sectarismo, do fundamentalismo. Vivemos um momento de crise aguda, em que as referências disjuntivas e simplificadoras não conseguem dar conta de problemas cada vez mais complexos da modernidade, como as questões socioambientais, o que gera nas pessoas grande instabilidade psicológica e medo diante de uma nova realidade desconhecida. Diante deste estado de grande insegurança, há uma forte tendência inata de se buscar referências e valores do passado, que psicologicamente nos dão a sensação (simplista) de segurança do já conhecido. Isso tem levado a se valorizar as soluções neste mesmo modo de pensar e agir já conhecido, reproduzindo percepções e valores espelhados nos paradigmas da modernidade. Isso vem recrudescendo os sentidos de um nacionalismo disjuntivo dicotômico, do individualismo do "meu primeiro", do "American First" de Donald Trump, pelo mundo afora; do conservadorismo de uma volta ao passado conhecido; do fascismo autoritário dos autoeleitos superiores, e outras manifestações que recorrem a posturas particularistas excludentes disjuntivas reacionárias que dicotomicamente separam e excluem pela dominação. Questões que justamente vêm produzindo a degradação em escala planetária dessa gravíssima crise socioambiental da atualidade.

\section{DIMENSÕES DA CRISE}

Diante da crise em sua complexidade civilizatória e a respectiva crise paradigmática que a acompanha, tem-se difundido no mundo as orientações políticas e econômicas do Neoliberalismo, fruto do paradigma disjuntivo, o que dificulta perceber soluções que sejam amplas, voltadas para a inclusão numa totalidade societária socioambientalmente sustentável e, portanto, acentuando a crise. 
O Neoliberalismo é uma proposta que busca resposta recorrendo e acirrando os paradigmas disjuntivos, quando aposta que o que deve motivar e mover as relações socioeconômicas são os estímulos dados às iniciativas privadas (dos indivíduos, do particular), regulados centralmente pelas leis de mercado, sem a interferência do Estado. $\mathrm{O}$ Estado Mínimo defendido é o enfraquecimento deste ente coletivo - Público - na regulação das relações econômicas e sociais. É deixar que os entes privados e seus interesses econômicos particulares sejam os definidores das relações estruturantes do modo de viver dessa sociedade. É fazer com que a meritocracia prevaleça, em que cada um por si, com sua "livre iniciativa" e a "livre concorrência" privilegie o mais capaz (forte), o que levará a promover, dessa forma, o desenvolvimento das forças produtivas geradoras de riqueza do sistema e seus mecanismos de acumulação. Certamente, com a "liberdade" da iniciativa privada, sem a regulação de um ente público, que visa a moderação de desequilíbrios nas relações sociais, os indivíduos (partes) e os segmentos mais fortes que constituem uma elite, fazem com que os interesses particulares dessa elite se sobreponham ao interesse coletivo popular. Se o resultado esperado é o crescimento da economia, poderão até obter, mas as relações de poder que dominam e exploram o outro, indivíduo, classe, nações periféricas, natureza, essas serão acirradas com a consequente intensificação das degradações socioambientais. Não há políticas Neoliberais para combater a desigualdade social e delimitar a degradação do meio ambiente; pelo contrário, essas são vistas como gastos e empecilho ao crescimento econômico. Tudo isso agrava a imensa crise que estamos vivendo, como reflexos de sua dimensão paradigmática.

Tudo isso reforça a perspectiva excludente, disjuntiva e fragmentária que está no cerne da crise civilizatória, que tem na ideia da prevalência do mais forte, da particularização dos interesses, do "cada um por si”, a exacerbação do egoísmo narcisista de um indivíduo ensimesmado em um egocentrismo. Valores de uma modernidade líquida ${ }^{1}$ e efêmera, como diria Bauman (2001), estruturantes da dissolvência da noção de comunidade, do coletivo, de uma sociedade que tenha um propósito em comum, do público, da solidariedade como fundante das relações. A princípio, pode parecer paradoxo a noção de Nacionalismo, como espaço identitário de um coletivo comum, sendo propagado junto à efetivação desse Neoliberalismo no mundo. Porém, o que referencia esse Nacionalismo de extrema direita em curso é a mesma perspectiva disjuntiva e excludente do Neoliberalismo. A mesma que historicamente sustenta os poderosos e a predominância de seus interesses particulares como,

\footnotetext{
1 "O conceito de modernidade líquida nasce de um diagnóstico de época, em que a contemporaneidade é construída através dos pilares frágeis da insegurança e do consumo. Assim, a vida se torna líquida, ausente de referenciais morais e políticos, um mundo de consumidores, de indivíduos atomizados responsáveis solitários pelo sucesso e fracasso de suas próprias vidas." https://colunastortas.com.br/modernidade-liquida/. SIQUEIRA, Vinicius. Zygmunt Bauman: a biografia de uma lenda. Colunas Tortas, 2015. Acesso em 25 de jun. de 2019.
} 
o de "meu país/eu primeiro" que está implícito no "American First"; que faz dos refugiados e dos imigrantes de outras nações, inimigos. A defesa dos "meus" valores tradicionais, o que faz a estes entenderem os outros como diferentes e inferiores. Diferenças que para eles destroem seus valores e assim devem ser perseguidos e marginalizados, como os que têm diferentes orientações sexuais, os que reivindicam igualdades nas relações étnicas, de gênero e de outras crenças religiosas. Como também os que defendem regulações para uma sociedade mais igualitária, que são estereotipados como “comunistas antipatriotas". Ou seja, tudo e todos que questionam uma ordem historicamente hegemônica instituída por meio da imposição dos interesses econômicos, valores e costumes de uma elite dominante.

Ao neoliberalismo, que favorece a predominância do mais forte e que detém, portanto, o poder, se junta uma visão nacionalista. Visão essa de que a nação deve estruturar-se a partir dos valores dos dominantes, "tradicionais", e que, portanto, os interesses privados, dos poderosos certamente, devem ser privilegiados sem a presença de um Estado regulacionista. Para esses, o Estado quando cumpre a função distributivista, retira recursos do mercado, o que "pesa" no crescimento econômico e, assim, na geração e acumulação da riqueza dos mais fortes e da elite política e econômica de cada nação. Dessa forma, neste mundo globalizado, em que o capital (principalmente financeiro) se transnacionalizou, os interesses privados das elites das diferentes nações se interligam pelo mundo transnacionalizado, não se limitando aos interesses nacionais. Porém, Estados em que o Neoliberalismo se hegemoniza, a sua presença mínima, mas dominada pela elite e seus representantes, é garantidora dos mecanismos de uma economia de livre mercado. Assim fecha o ciclo que potencializa as boas condições para as elites econômicas, em sua bidimensionalidade nacional e transnacional - reproduzir este modo de acumulação econômica globalizado. Porém, ao mesmo tempo, a manutenção desse processo de reprodução e acumulação crescente do capital vem, exponencialmente, acentuando a postura excludente nas relações sociais e a intensificação da destruição do meio ambiente; moto contínuo das relações de degradação socioambiental e intensificadora da grave crise mundial.

A tudo isso, serve de contexto para uma grave denúncia de Bruno Latour (2019),

Tudo parece indicar que uma boa parte das classes dirigentes (o que hoje se chama, de forma muito imprecisa, as "elites") chegou à conclusão de que já não há suficiente espaço na Terra para elas e para o resto de seus habitantes. Por conseguinte, as elites concluíram inútil a ideia de que a história se dirige a um horizonte comum onde "todos os homens" poderemos prosperar de igual maneira. (Latour, 2019, p.12. Tradução do autor)

Considera-se a possibilidade de descarte pela exclusão do seu semelhante, pelo abandono à deriva, à própria sorte de um náufrago refugiado; pelo cultivo de sentimentos de ódio ao vulnerável e às minorias. Essa perspectiva aponta a dimensão de mais uma grave crise e que se 
interagem! A crise ética de perda de fundamentais valores humanos. O descompromisso com a manutenção da vida, do cuidado com o outro como garantia da própria continuidade da vida humana, como na força maternal diante do perigo para sua cria. Da ação solidária nas relações, como forma e estratégia de sobrevivência dos indivíduos e da espécie. Valores esses fundamentais para garantir os humanos em sua humanidade até os dias atuais. $\mathrm{O}$ ataque e a dissolvência ética desses valores nos colocam a barbárie no horizonte. São esses fortes indicadores de que vivemos uma gravíssima crise de um naufrágio civilizatório.

A grande ameaça da morte trágica é o que verdadeiramente nos une. $\mathrm{O}$ risco da extinção da vida humana ou até mesmo a vida como um todo, a vida de Gaia ${ }^{2}$, é o grave cenário que o câmbio climático nos apresenta. Hoje, agora, vivemos essa grande ameaça e olhamos para ela como se não fosse algo tão grave assim, que está longe de nossas vidas. Entretanto, nossas vidas, de todos, estão em grande risco!

O que a ciência mundial nos coloca, com um quase consenso absoluto, é que a degradação do meio ambiente, na escala planetária que alcançou, está em ponto de colapsar o equilíbrio ecológico que mantém as atuais condições que conhecemos para a reprodução da vida na biosfera; ou seja, em todo o Planeta Terra.

Costumamos pensar que os fenômenos se desenrolam numa sequência progressiva e que com o tempo, com a acumulação dos impactos é que chegaremos a uma grande situação caótica. Acreditamos que nessa acumulação, teremos tempo e que a tecnologia resolverá tudo. Os estudos nos mostram cada vez mais que estes não são os fatos!

Realmente, o equilíbrio ecológico tem uma capacidade de reter uma progressiva tensão, o que os ecólogos chamam de resiliência, sobre suas flexíveis redes de relações, mas a teia da vida um dia pode se romper! A ruptura desse equilíbrio provoca de imediato uma forte reação em cadeia, que produz um caos na ordem anterior, na forma como os fios eram tecidos e que sustentavam aquelas condições de vida. Nessa ruptura, quem viver, viverá o caos! Uma situação de tal magnitude que vivê-la, os que sobreviverem, estarão conhecendo algo talvez próximo as alegorias do que se chama de inferno! E a Educação Ambiental diante de tal cenário?

\section{MUDANÇA CLIMÁTICA NÃO EXISTE... MAS É REAL}

"Se as pessoas definem uma situação como real, ela acaba sendo real nas suas consequências."

(William I. Thomas, 1928)

A mudança climática não existe, pelo menos ela não existe como um fenômeno específico ou um conjunto de fenômenos concretos que são claramente discerníveis para as pessoas em seu espaço-tempo diário. Podemos perceber o tempo meteorológico, mas não o

\footnotetext{
${ }^{2}$ Muitos advogam que a vida de Gaia é bem mais resiliente que a Humana. Referimo-nos ao planeta Terra como Gaia, assim como Lovelok \& Margulis (1974) em sua Hipótese Gaia.
} 
clima, sem falar nas flutuações de seus parâmetros ao longo de períodos, de décadas, séculos ou milênios. A mudança climática - como o clima - é uma representação científica. Ao mesmo tempo, apenas no aparente paradoxo, a representação científica sintetizada no conceito "mudança climática" - ou no conceito "clima" - nos ajuda a entender a realidade, interpretá-la e, na medida em que consideramos essa interpretação compreensível, ela permite orientar nosso comportamento em relação a essa realidade, principalmente se ela estiver ameaçando a nós, como indivíduos, como sociedade e como espécie. Brincando com o chamado Teorema de Thomas: Quando interpretamos e valorizamos "objetos" que apenas a ciência pode representar em sua complexidade, se definirmos uma situação como irreal, ela acaba sendo real em suas consequências. Ou seja, se na luta social para determinar se a mudança climática é real ou se é causada ou não pela interferência humana no balanço de radiação da atmosfera, são impostas teses negacionistas ou céticas (em suas diferentes versões), essa representação (social) não nos livrará das consequências que a mudança climática tem e, acima de tudo, se projetará a médio e longo prazo para toda a humanidade.

Estamos em plena época em que negacionistas de diferentes sinais e estratégias argumentativas, disputam os sentidos com a ciência em relação às questões ambientais que nos afligem. Como Ulrich Beck (2000) previu, “a crise ecológica está sendo questionada. Um dia alguém vai querer argumentar que essa crise só existe na mente das pessoas. ”

Há crise ambiental? A sociedade humana, em seu atual modo hegemônico de produzir e consumir, é a grande responsável por essa crise? A crise é grave como afirmam a grande maioria dos cientistas debruçados sobre esta problemática? As mudanças climáticas são os sinais mais presentes, imediatos e emergencial, como se propala no meio científico? Essas questões se aceitas como reais, significam a necessidade de grandes rupturas e transformações no modo de vida atual, o que certamente acarretará grandes mudanças nas atuais estruturas sociais. Mudanças e transformações radicais não são situações muito assimiláveis pelas elites beneficiárias deste modelo, que mantêm esses privilégios pela relação de poder, exercendo domínio das dinâmicas sociais e econômicas para se favorecer, inclusive com o domínio sobre as narrativas que prevalecem sobre as pessoas em geral e suas representações. Ou seja, estão fortemente interessadas que a crença na gravidade desta situação não seja tão real assim.

O público 'crê' que o mundo externo é objetivamente real, mas aqui nasce precisamente a questão: qual é a origem desta 'crença' e que valor crítico tem 'objetivamente'? (Antônio Gramsci, 1999)

Neste momento histórico, a crise aponta para graves repercussões na própria continuidade da vida no planeta. A Ciência sinaliza com limites e pontos de não retorno para o processo de degradação das condições de manutenção da vida nos atuais padrões. Sendo assim, a forma como a população percebe, representa este momento e reage a ele é de extrema 
importância para demarcar a atuação do educador ambiental. De fato, assumir e conviver com essa condição póstuma (GARCÉS, 2017) pode nos colocar na frente uma nova geração de educadores ambientais. Uma geração que terá de enfrentar o colapso da civilização ao lidar com a modernidade que se torna hegemônica em sua fase do capitalismo global de mercado. A Educação Ambiental (EA) apareceu nos anos sessenta e setenta do século passado, com um viés claramente reformista e voluntarista, como ferramenta para reduzir os efeitos degradantes na biosfera de uma civilização que absorve cada vez mais recursos e emite mais e mais detritos. Agora essa EA terá que se reinventar. Isso coloca o cenário educacional na situação de um colapso socioambiental que já podemos estar enfrentando, sem estar totalmente ciente de sua radicalização e seu momento histórico. Uma das características mais paradoxais dessa condição póstuma é o que Marina Garcés chama de analfabetismo ilustrado, ou seja, "sabemos tudo, mas nada podemos fazer. Com todo o conhecimento da humanidade à nossa disposição, só podemos restringir ou acelerar nossa queda no abismo " (Garces, 2017). A mudança climática é a melhor expressão da condição póstuma em que a EA terá que operar à medida que o século XXI progride: enquanto a representação científica objetiva representa a crise climática e a mudança global que implica - mais ou menos catastrófica segundo agirmos na próxima década - civilização humana continua a operar dentro da estrutura estabelecida pelo capitalismo de mercado global.

A Conferência do Clima em Paris, de 2015, estabelece em suas resoluções parâmetros acordados como forma de enfrentar, para remediar e adaptar as condições do desenvolvimento a limites climáticos suportáveis, deram como concreto que o aumento da média do aquecimento global é de $+1,5^{\circ} \mathrm{a}+2^{\circ} \mathrm{C}$ até o final do século. Exceder esse limite de temperatura colocaria a humanidade na zona de sofrimento. De acordo com os cenários tratados pelo IPCC (2018), para atingir esse objetivo será necessário seguir um caminho para reduzir as emissões de gases de efeito estufa, a fim de que nos leve a meados do século com a metade das atuais emissões e assim ter a possibilidade de chegar ao final do século XXI com a emissão zero (é dizer, tantas emissões anuais como são capazes de absorber os sumidouros naturais de CO2). Nesse caminho, os próximos dez anos, com o ano 2030 como horizonte imediato, serão cruciais. Atender esse caminho de redução de emissões requer mobilização global e uma ruptura profunda com os modos atuais de produção e consumo, principalmente nos países mais desenvolvidos. Para que haja motivação e mobilização para iniciativas que levem a essas rupturas, a crença compartilhada entre indivíduos e sociedade de que é real a gravidade da crise será fundamental.

Como a educação ambiental, por intermédio de seus educadores, podem contribuir com as mudanças no juízo de valor da população, que coadune com o processo de transição para um outro modo de vida? 
A pesquisa social identificou algumas barreiras que dificultam o trabalho educacional, especialmente quando há poucos recursos e sem políticas públicas de educação e meio ambiente que considerem transversalmente o papel da educação institucionalizada, e não formal, no enfrentamento da crise climática. As primeiras barreiras estão associadas a déficits e distorções na compreensão da mudança climática antrópica por toda a sociedade: os processos biofísicos envolvidos; a maneira como ela interfere na atividade humana; as consequências de alterar a atmosfera para a humanidade; a biosfera e suas implicações econômicas, políticas, energéticas e políticas sociais para adaptação e mitigação. As barreiras ao conhecimento derivam de duas características da crise climática. Antes de tudo, a mudança climática é um fenômeno hipercomplexo e abstrato do ponto de vista da cultura comum, na medida em que só pode ser representada levando em consideração a representação da ciência pela ciência. De fato, um número significativo de pessoas acredita que a mudança climática é real sem acreditar que a comunidade científica tenha plena certeza de que é assim (MEIRA, ARTO, HERAS, IGLESIAS, LORENZO E MONTERO, 2013). Em segundo lugar, também é um fenômeno contraintuitivo que tende a ser confundido com aspectos relacionados à natureza caótica - ou aparentemente caótica - da percepção da cultura comum, do tempo e da confusão entre o tempo e o clima. Sempre que uma onda de frio que afeta o sul dos Estados Unidos, associada à desestabilização de correntes no aquecimento do Ártico, a mídia negacionista é preenchida com vinhetas supostamente bem-humoradas que procuram demonstrar a aparente contradição entre um planeta em aquecimento e o gelo cobrindo os pântanos da Flórida ou as praias da Califórnia. O mesmo ocorre quando chuvas torrenciais ocorrem em locais tradicionalmente secos, enquanto a suposição comum da cultura é que os processos de desertificação são exacerbados. Não relacionando esses fenômenos extremos e fora de época como sendo justamente uma das características das consequências das mudanças climáticas.

Um segundo conjunto de barreiras dificulta que as pessoas avaliem a gravidade e o imediatismo das ameaças associadas às mudanças climáticas. Estudos de opinião pública mostram que as mudanças climáticas geralmente não são um dos problemas que mais inquietam e preocupam uma sociedade, tendo uma relevância social relativamente baixa. $\mathrm{Na}$ sua hierarquia de problemas e necessidades, as pessoas frequentemente apresentam os problemas que têm a ver com a satisfação imediata de suas necessidades, economia, bemestar, saúde e segurança a curto prazo. Diante dessas prioridades, as mudanças climáticas e suas consequências são frequentemente percebidas como distantes no espaço (afetam ou afetarão outras pessoas em outros lugares) e no tempo (seus impactos ocorrerão no futuro a médio ou longo prazo), fora da expectativa de vida da população com mais capacidade de tomar decisões de resposta diante da ameaça. Essa distância psicológica é alimentada pelo 
lugar secundário da crise climática na agenda pública (social, política, cultural, educacional etc.), que alimenta a irrelevância, inibindo o impulso individual e coletivo de agir.

Um terceiro tipo de barreira para lidar com a crise climática decorre da dificuldade de traduzir a consciência de sua existência e seu potencial de ameaça, em ações de resposta coerentes e eficazes, individual e coletivamente. Uma primeira barreira é a sobredeterminação que cria a ameaça da crise climática nas pessoas. A sobredeterminação é uma emoção mista, que combina o medo que inspira um mundo degradado pela alternância do clima e a impotência percebida do indivíduo, que entende que sua resposta é insignificante diante da magnitude e da globalidade da ameaça. A sobredeterminação é uma emoção paralisante que muitas vezes leva à inibição: de que serve se preocupar com um problema diante do qual a ação individual é percebida como irrelevante, ineficaz ou inútil. Outras barreiras à ação decorrem da dificuldade em encontrar microcontextos e macrocontextos que facilitam comportamentos coerentes com o conhecimento do problema e a conscientização de que ele é relevante. Essas barreiras situacionais atuam como obstáculos estruturais: por exemplo, de pouco serve apostar no nível individual no uso de transporte público se residirmos em uma sociedade em que a infraestrutura de transporte e a organização urbana são projetadas para favorecer o transporte privado. Nos cenários da vida cotidiana, são impostas as rotinas associadas ao modelo energético determinado pelo uso intensivo de combustíveis fósseis, desde o âmbito das tecnologias até ao dos estilos de vida (alimentação, consumo, mobilidade, lazer, relações sociais, cultura, etc.). Apesar de tomar consciência da crise climática e assumir formalmente valores e padrões comportamentais alternativos, com o objetivo de reduzir a pegada de carbono individual e coletiva, os contextos em que vivemos - principalmente nas sociedades mais desenvolvidas - continuam a operar com a lógica estrutural de um mundo alimentado por energia fóssil. Contextos determinados por orientações políticas e econômicas que continuam a operar sob o mito do crescimento como premissa para o desenvolvimento humano sustentável. De fato, como destacado por Gonzalez-Gaudiano (2019), pode-se afirmar que a principal "barreira cultural" para a transição ecológica necessária é a natureza estrutural da crise climática: suas implicações naturais e humanas, seus efeitos agregados e complexos, sua expressão espacial e temporal, seus medos de incerteza científica, suas implicações políticas e éticas, sua complexidade multicausal; a incoerência entre mensagens científicas e as políticas de resposta, o culto ao progresso e aspirações ao "desenvolvimento", otimismo tecnológico, etc.

A necessidade de superar essas barreiras para responder à crise climática na janela temporal de oportunidade que a ciência identifica na próxima década, obriga a estabelecer estratégias educacionais de emergência. Essas estratégias devem ser adaptadas a cada contexto social, centradas na mitigação nas sociedades com mais emissões de gases de efeito 
estufa e na adaptação nas sociedades com menos carga nas emissões, mas geralmente mais vulneráveis aos seus efeitos, com três desafios principais:

- Em primeiro lugar, é preciso que a população considere a relevância das mudanças climáticas; perceber seu potencial de ameaça; colocá-la no centro de sua agenda pessoal e ser capaz de valorizá-la como uma ameaça real e iminente. Essa conscientização será fundamental para indivíduos e sociedades apoiarem políticas de mitigação e de adaptação mais radicais, como também se envolverem em sua implementação. Esse processo de conscientização deve evitar sobredeterminação, ou seja, a paralisia individual e coletiva que leva aos piores cenários da crise climática quando se apresentam, sem propor alternativas para evitá-los e sem oferecer formas eficazes pelas quais as pessoas possam participar da realização de políticas de mitigação e adaptação.

- Em segundo lugar, e paralelamente à tomada de consciência, é necessário desenvolver processos educacionais que estabeleçam conexões significativas entre indivíduos e as comunidades com as mudanças climáticas. Diante de um problema que parece representar-se como abstrato e ser percebido como psicologicamente distante, é necessário estabelecer vínculos entre as mudanças climáticas e as dimensões da vida cotidiana que mais preocupam as pessoas e comunidades: saúde, alimentação, segurança, economia (cotidiana), moradia, acesso à água potável, qualidade do ambiente nas proximidades, etc. Nesse sentido, é necessário que as pessoas deixem de ser consideradas indefesas e alheias às causas dos problemas, identificando $\mathrm{e}$ assumindo suas responsabilidades e corresponsabilidades em causas e soluções, para que deixem de ser vistas apenas como vítimas passivas e impotentes, e possam adotar um papel cidadão proativo.

- Em terceiro lugar, é preciso internalizar a urgência de agir, dada a inércia das ações no sistema climático e a magnitude das intervenções necessárias para limitar a mudança para $+1,5^{\circ} \mathrm{ou}+2^{\circ} \mathrm{C}$ até o final deste século. Essa urgência em agir deve ser internalizada em todos os níveis e instituições sociais. Precisamos articular, por exemplo, um currículo educacional de emergência climática. Um currículo que coloque a crise climática entre as prioridades em todos os níveis de ensino, principalmente no ensino obrigatório. A temática das 
mudanças climáticas tem de deixar de ser considerada um tema a mais no currículo, para ser tratado como um problema cuja resolução marcará o futuro da humanidade. O futuro de gerações de estudantes que estão agora no sistema educacional nesta década serão as gerações da mudança climática: a qualidade de suas vidas será determinada pela eficácia das respostas que sejamos capazes de dar agora. A descarbonização acelerada de nossas sociedades exige que todos os recursos institucionalizados de socialização operem com esse objetivo. O artigo 12 do Acordo de Paris convida os países signatários a alinhar suas políticas educacionais à política climática, mas sua transposição para a prática curricular e a ativação de recursos educacionais não formais foram praticamente nulas. Quantos sistemas educacionais atuais incorporaram a resposta à crise climática como pedra angular e objetivo primordial da política educacional? Quantos países vincularam diretamente suas políticas de mitigação e adaptação às políticas nacionais de educação?

O que se verifica até aqui é a gravidade e urgência da crise, em que o ano de 2030 é sinalizado como decisivo para os rumos da humanidade. Para nós, essas referências caracterizam o câmbio climático como sendo gerado pela forma como o modo de produção e consumo globalizado demonstra sua insustentabilidade, resultando na crise do modelo civilizatório da modernidade. É nesse contexto de crise que pensamos na urgência de uma educação ambiental crítica, transformadora e emancipatória, que contribua no processo de construção da transição para uma sociedade socioambientalmente sustentável.

A esta urgência cabe adicionar a necessidade de uma resposta global; pouco resolve que uma sociedade ou um grupo social empreenda o caminho da transição ecológica, senão se produz uma articulação concertada a nível global, tal e como pretende o Acordo de Paris. A maior responsabilidade reside, porém, nos grandes emissores dos Gases de Efeito Estufa. O Climate Action Tracker e Climate Transparency analisaram nos países do G20 a contribuição nacional projetada (INDC), o que os governos propõem mitigar, as políticas efetivas implantadas (em 2017), o que realmente estão fazendo para a redução das emissões de gases de efeito estufa, tendo como horizonte seu alinhamento ao cumprimento do Acordo de Paris. O resultado dessa avaliação é mostrado na Figura 1: com exceção da Índia, as políticas climáticas propostas e implementadas nos países do G20 são insuficientes e, em alguns casos, criticamente insuficientes, para atingir as metas estabelecidas em Paris para limitar o aumento da temperatura abaixo $2{ }^{\circ} \mathrm{C}$ e, obviamente, $1,5^{\circ} \mathrm{C}$ (Sachs, Schmidt-Traub, Kroll, Lafortune, Fuller, 2018). O que realmente preocupa nesse gráfico é que as sociedades representadas nele somaram mais de $80 \%$ das emissões globais de gases de estufa de origem fóssil no ano de 2017. 


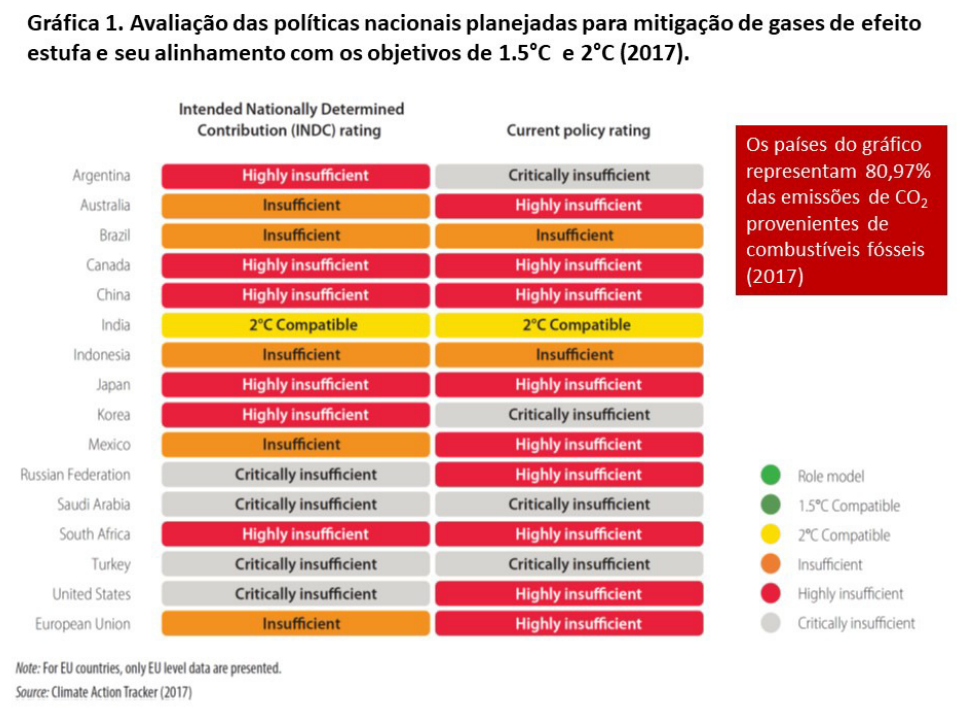

O que a Ciência nos diz é que estamos vivendo hoje um grave dia da história da humanidade, em que em poucas horas essa teia da vida irá se romper. A reação em cadeia que virá, com megaimpacto sobre as condições ambientais que mantém as atuais formas de vida, inclusive a nossa humana, é imprevisível e aterradora! Temos todos poucas horas! O que fazer? Fios isolados não formam uma teia. Tentar se safar cada um por si? American First? Será a confirmação da denúncia de Latour? Há uma rota de fuga, em que as elites mundiais estão correndo para pegar os poucos botes salva vidas do Titanic para se salvarem, deixando a própria sorte os não privilegiados? Grande ilusão! Somos todos vulneráveis passageiros em uma nave muito maior e que nesta forte tormenta, estes botes são muito mais frágeis, reduzidos e limitados para enfrentar esta crise. Essa postura individualista e excludente é que tem levado a todos nós a essa situação de degradação social, ambiental, ética. Continuar buscando a rota de fuga, reproduzindo o mesmo caminho que nos trouxe até aqui, isso é continuarmos vivendo o naufrágio, presos na armadilha paradigmática ${ }^{3}$.

Diferentemente a Latour, apostamos otimisticamente que pelo menos parte das elites mundiais manifestam essa postura excludente da estrutura de pensamento disjuntivo da modernidade, por se encontrarem presos inconscientemente à armadilha paradigmática. A cegueira produzida por essa armadilha é o naufrágio de todos, porque todos somos vulneráveis quando buscamos enfrentamentos particularizados. Individualmente somos fracos e na busca histórica da sobrevivência sempre fomos seres sociais colaborativos. Os botes

\footnotetext{
${ }^{3}$ É a essa dinâmica que estou chamando de armadilha paradigmática, quando por uma "limitação compreensiva e uma incapacidade discursiva" (Viégas, 2002), o educador, por estar atrelado a uma visão (paradigmática) fragmentária, simplista e reduzida da realidade, manifesta (inconscientemente) uma compreensão limitada da problemática ambiental e que se expressa por uma incapacidade discursiva, que cria amarras para o desenvolvimento de uma visão crítica e complexa do real, refletindo em uma prática pedagógica fragilizada de educação ambiental, produzindo o que Grün (1996) chamou de pedagogia redundante. Essa prática pedagógica presa à armadilha paradigmática não se apresenta apta a fazer diferente e tende a reproduzir as concepções tradicionais do processo educativo, baseadas nos paradigmas da sociedade moderna, sendo esse um poderoso mecanismo de alienação ideológica e de manutenção da hegemonia.” (GUIMARÃES, 2013)
} 
salva-vidas são muito mais frágeis para enfrentarem a tormenta; o navio tem maiores possibilidades. A diversidade e a sinergia de todos embarcados no navio é que poderão potencializar a superação da tormenta.

Estarmos como educadores ambientais conscientes desse risco e enfrentá-lo com as nossas forças é estarmos juntos investindo, com prioridade absoluta, no que pode nos levar a mudar a tensão que se faz sobre a teia da vida. Como sociedade, temos de estar abertos e fortemente intencionados em viver sob novas relações entre nós e com o meio ambiente. Isso significa termos que abrir mão do atual modo de vida, das expectativas e desejos que alimentam nossos atuais sonhos de futuro trocando-os por outros, de nos desbravar diante do medo que o desconhecido nos traz, para a construção de outro mundo possível.

Fortalecer e potencializar visões contra-hegemônicas na práxis dos educadores ambientais, capazes de dinamizar o enfrentamento dos três grandes desafios descritos anteriormente, propicia ampliar o movimento de construção de uma sociedade socioambientalmente sustentável.

A prioridade para as transformações significativas que precisamos implementar passa fundamentalmente por pressionar os tomadores de decisões para políticas de investimento em Educação, Ciência e preservação ambiental; assim como de combate à desigualdade social. Transformações que se voltem para criar as condições de um novo modo de vida, em que as relações em equilíbrio das partes com o todo sejam o que estruturem dialogicamente um novo modo de organização social em um novo modo de produzir e consumir na relação com a natureza. Relações que distencionem a teia da vida e permita, na resiliência, trançarmos novos fios na teia.

O caminho negacionista de atacar e desacreditar a Educação, a Ciência e a necessidade de preservação ambiental, como também o incentivo à concentração de renda das políticas neoliberais, como tem acontecido em movimentos reacionários de conservação do status quo que se empoderam no Brasil e outros lugares do mundo, nos aproximam cada vez mais deste ponto de ruptura, do caos e da barbárie e isso afeta a todos!

Porém, diante de uma catástrofe como as mudanças climáticas nos anunciam, na vivência de uma experiência significativa transformadora, o espírito humano solidário sempre se apresenta. Estarmos consciente da grande ameaça da morte e da barbárie é o que verdadeiramente nos une, e como a sabedoria popular nos indica, "a união faz a força". Eis um bom e novo caminho a seguir, a conquistar e transformar! 
Ensino, Saúde e Ambiente - Número Especial, pp. 21-43, Junho. 2020

\section{RADICALIDADE DA CRISE, TRANSFORMAÇÕES SIGNIFICATIVAS E EDUCADORES AMBIENTAIS}

Há uma ideia predominante na modernidade disjuntiva que para se chegar a uma totalidade, somamos as suas partes. Isso não é errado, mas é uma possibilidade reduzida e simplificadora. Por exemplo, a ideia da ação coletiva como sendo a soma das partes, do $1+1$ que é realmente 2 (que é melhor e maior do que apenas 1), no entanto isso não supera a perspectiva disjuntiva do paradigma da modernidade, que se estrutura a partir do "Um" fundante do neoliberalismo, do individualismo, da parte, do particular no capitalismo. Para pensarmos para além disso, podemos usar a analogia de que a superação se dá na ideia ${ }^{4}$ do 1 com $1>2$, porque aqui pode ocorrer na interação das partes a sinergia (força resultante que vai além da soma das partes), numa relação integrativa de complementariedade; importante força para a pressão social no confronto pelo embate hegemônico. O 1+1 pode se restringir a ideia reduzida da participação das redes sociais, em que 1 por trás do computador isolado do outro 1 são 2 (que é melhor e maior do que apenas um); cada um assina o manifesto de protesto e ao final temos a soma dos "participantes" protestando. Porém, o resultado disso em maior interação, por exemplo, das pessoas juntas manifestando nas ruas, é bem maior pela sinergia, que se dá pela interação que se fortalece na relação autovigorante do 1 com 1. Essa sinergia é fundamental para dinamizarmos e potencializarmos os movimentos contrahegemônicos de construção de outros modos de vida, de produzir e consumir, que seja sustentável.

Podemos usar dessa analogia para problematizar uma ideia que muito se repete em educação ambiental, a de "cada um fazer sua parte", que se for pensada apenas cartesianamente na parte, ela reforça a perspectiva disjuntiva, voltada para a ação individual. É essa concepção que faz com que nós professores aceitemos, por exemplo, um trabalho de grupo (coletivo) como cada um fazendo uma parte e reunindo as partes num somatório de trabalhos individuais.

A práxis destes educadores ambientais impera superar essa armadilha do paradigma que tende a nos colocar numa postura conservadora reprodutivista de uma educação comportamentalista do indivíduo. A radicalidade dos desafios que se apresentam se faz necessário promover nos processos formativos de educação ambiental uma constante postura reflexiva crítica, que passa pela reforma de um pensamento disjuntivo, para um pensamento complexo (Morin, 1999) em que se desfoca da parte unicamente e se percebe as relações entre

\footnotetext{
${ }^{4} \mathrm{O}$ maior que dois como uma possibilidade mais complexa e ampliada de totalidade do que a totalidade igual a dois, como resultado da soma das partes.
} 
as partes, as partes e o todo e do todo com as partes. Em relações que são conjuntamente antagônicas, complementares e concorrentes.

Acreditamos ser importante potencializar movimentos contra-hegemônicos na sociedade, que tragam essa perspectiva crítica, transformadora e emancipatória, que promovam o enfrentamento dos três grandes desafios apresentados rumo a uma transição civilizatória e que educadores ambientais possam ser agentes dinamizadores desse movimento.

Portanto, a superação dessa armadilha em nosso cotidiano, para nós educadores ambientais, por tão inconsciente e automatizado que está em nossas práticas, requer uma atenção constante certamente predisposta por uma postura reflexiva crítica que favorece a uma práxis transformadora. Entretanto percebemos que nós, como seres individuais e sociais complexos que somos, necessitamos ir além de uma percepção cognitiva que nos alimente, pela reflexão crítica, a razão. Somos seres integrais em que razão e emoção, corpo e espírito, indivíduo e sociedade se interagem e que isso se realiza na relação com o outro, com o mundo.

Em função disso, estamos desenvolvendo estudos que permitam nos dar indicadores de uma formação mais radical de educadores ambientais. Entendendo que a gravidade e urgência da crise que vivemos, requer educadores comprometidos, como militantes radicais (que vão à raiz) dessa causa, como "sujeitos ecológicos" capazes de superar as armadilhas paradigmáticas, dinamizando movimentos sociais contrahegemônicos em suas esferas públicas de atuação.

Em função disso, nessa proposta consideramos importante pesquisar ${ }^{6}$ ambientes $^{2}$ educativos $^{7}$ que possam propiciar experiências significativas $^{8}$ de ruptura da Armadilha

\footnotetext{
${ }^{5}$ Para Isabel Carvalho (2004) "Sujeito ecológico, em poucas palavras, é um modo de ser relacionado à adoção de um estilo de vida ecologicamente orientado. Trata-se de um conceito que dá nome àqueles aspectos da vida psíquica e social que são orientados por valores ecológicos. O sujeito ecológico pode ser ainda descrito como um ideal ou uma utopia internalizado pelos indivíduos ou pessoas que adotam uma orientação ecológica em suas vidas."

${ }^{6}$ Com o apoio do Grupo de Investigación en Pedagoxía Social e Educación Ambiental (SEPA), da Universidade de Santiago de Compostela, investigamos as possibilidades formativas da vivência do Caminho de Santiago, como um ambiente educativo propício à formação de educadores ambientais.

${ }^{7} \mathrm{O}$ ambiente educativo que buscamos constituir nesta proposta é de um espaço tempo dinamizado por relações provocativas, incentivadas por princípios formativos para potencializar experiências significativas sincronicamente vivenciais, do indivíduo, de um com outro (indivíduo/sociedade), de um com o mundo (natureza).

${ }^{8}$ Compreendemos assim como Jorge Larrosa Bondía (2002) que a experiência "é o que nos passa, o que nos acontece, o que nos toca" o que preenche de sentido significativo no processo formativo do educador em transformação e transformador em sua práxis. Entende-se como significativo que o religar a natureza em um sentido sacralizado, leva a vivenciar e perceber essa relação como uma interação vital, não somente para a sobrevivência física, mas em seu sentido de transcendência e realização da humanidade em um fazer integrado aos movimentos da natureza. Um saber vivencial (de experiência em Larrosa) em construção que contemple essa
} 
Paradigmática, promovidas por convivências de práticas individuais-coletivas em outros modos de vida, baseadas em padrões relacionais e referências epistemológicas diferentes da modernidade. Nessas pesquisas, valorizamos as comunidades e culturas locais, seus saberes tradicionais e ancestrais, assim como outras iniciativas comunitárias, realidades outras, diferentes do modo de vida da modernidade, vivenciados em experiências significativas.

Assim, estamos desenvolvendo uma proposta teórico-metodológica, que denominamos de "ComVivência Pedagógica", a qual busca evidenciar um processo formativo em intensa vivência com outras epistemologias e modos de vida, potencializando experiências significativas demarcadas pela centralidade no convívio dialógico entre indivíduos, sociedade e natureza. Esse processo formativo propõe imersões que provoquem um choque de realidade por experiências vivenciais dos princípios formativos ${ }^{10}$, que estamos delineando na proposta:

- Desestabilização Criativa: princípio que provoca uma desestabilização das certezas impostas pelo determinismo da modernidade cientificista, rompendo com uma falsa segurança e estabilidade de algo já percebido como conhecido. Essa falsa sensação de segurança e de estabilidade decorre de referenciais introjetados em nosso inconsciente individual e coletivo (Paradigma Disjuntivo da modernidade). Pelo reconhecimento da crise paradigmática vivida (reflexão crítica) provoca-se o movimento de superação do pré-determinismo, que pouco contempla as incertezas do real, ainda mais em tempos de graves crises (indignação ética). As posturas possibilistas (que se opõem ao determinismo) potencializam que o novo possa surgir. Tudo isso é vivenciar relações de renúncia ao conhecido e a abertura para o novo (intencionalidade transformadora/postura conectiva).

- Reflexão Crítica: princípio que provoca uma postura problematizadora diante de uma realidade em que a gravidade e urgência da crise potencializa uma sensação de inquietude (desestabilização criativa). Sensação essa motivadora da não aceitação da realidade dada como tal (indignação ética) e mobilizadora na intervenção para uma realidade outra (intencionalidade transformadora) a qual se realiza no movimento transformador para além do individual (postura conectiva).

\footnotetext{
experienciação de estar no mundo em busca da completude do ser, em uma religação imanente com algo maior que nos transcende.

${ }^{9}$ Iniciadas no projeto de pesquisa "Outras epistemologias no processo formativo de educação ambiental", apoiado pelo MCTI/CNPq No 14/2013, no período de 2014/2015.

10 Os princípios formativos são entendidos como provocadores da dinâmica e orientadores das atividades vivenciadas nos ambientes educativos, constituindo-se como indicadores metodológicos da proposta.
} 
- Postura Conectiva: princípio que provoca uma ruptura com o modo de vida disjuntivo da modernidade (desestabilização criativa/intencionalidade transformadora). Esse modo de vida é calcado na hierarquização do poder que favorece relações reducionistas de dominação e exploração de um sobre o outro (reflexão crítica/indignação ética). Ao se romper com essa disjunção, a postura conectiva se torna possível pela vivência experiencial de relações dialógicas horizontalizadas, de sentimentos conectivos de pertencimento em suas complementares dimensões, social (sentido de comunidade), cultural (sentido de interculturalidade), espiritual (sentido de religare), ambiental (sentido planetário - Gaia).

- Indignação Ética: princípio que provoca a percepção existencial da indignidade da vida submetida a relações de opressão e submissão, contrárias aos princípios de sua livre expressão. Relações essas impostas por forças que obscurecem a manifestação da vida em sua plenitude singular, diversa e complementar ao outro. Conhecer a história das dominações opressoras (reflexão crítica) motiva um sentimento de ruptura com essas situações. Isso mobiliza a vivência de outras relações de dialogia não opressora, que superam a negação do outro. Essa superação, experienciada pela força da amorosidade (postura conectiva/intencionalidade transformadora), se dá pela inversão da prioridade do "eu" pelo "outro" que me antecede (sujeito ético).

- Intencionalidade Transformadora: princípio que provoca a construção do sentido na práxis do educador para a transformação da realidade. Práxis motivada pela percepção da crise civilizatória de um modo de vida disjuntivo, opressivo e degradante socioambientalmente (reflexão crítica), mobilizada (indignação ética) para intervir na superação dessas condições, pela vivência experiencial da amorosidade de novas relações conectivas (desestabilização criativa/postura conectiva).

Esses princípios certamente se interpenetram, como por exemplo, na busca da "intencionalidade conectiva" 11 para que a práxis do educador ambiental promova uma postura para fora, voltando-se, entre outras possibilidades, para a esfera pública do viver. Mesmo que seja, a princípio, uma ação individual, de cada um fazendo sua parte, porém com postura para fora. Um bom exemplo é o da jovem Greta Thumberg ${ }^{12}$. Greta começou protestando sozinha na frente do parlamento Sueco e juntou multidões. Isso quando ela, anteriormente, já não andava de avião, tinha mudado sua alimentação e hábitos de consumo, fazendo a sua parte.

\footnotetext{
${ }^{11}$ Se dá na interseção dos princípios formativos: intencionalidade transformadora e postura conectiva.

12 Jovem Sueca que aos 15 anos, em outubro de 2018, passou a fazer greve escolar todas às sextas feiras, se postando diante do parlamento com seu cartaz de protesto contra a passividade dos políticos em relação às mudanças climáticas. Sua iniciativa gerou um movimento global entre os jovens que se denomina "Friday for future".
} 
Dessa forma, sua ação, até então, voltava-se para dentro, numa real e importante mudança de sua esfera privada de vida. No entanto, enquanto assim reduzida a uma ação privada, sua ação teve pouca repercussão para transformações significativas da realidade coletiva, pois era uma ação ainda referenciada pelo paradigma disjuntivo que leva a ações individuais, particularizadas, voltadas para a mudança de comportamentos individuais somente em sua esfera privada de vida. O que se espera, a partir desta lógica disjuntiva hegemônica, é que o resultado dessas mudanças individuais de crianças e jovens, quando se tornarem adultos transformados, é termos uma sociedade transformada como resultado do 1+1. Já discutimos antes como isso é uma visão simplificada e reduzida da complexa realidade socioambiental. Porém, foi realmente quando Greta se colocou diante do parlamento, num espaço público, é que ela assumiu uma postura para fora de atuação na esfera coletiva de vida. A postura para fora propicia potência a essa ação para um "bom encontro" 13 , porque tendem a se juntar 1 com 1 que pode ser maior que 2 .

Pelo sentido da interconexão parte-todo, a manifestação da intencionalidade conectiva de se fazer diferente rompe com o "agir no automático", despertando para o consciente uma práxis que, ao se realizar conjuntamente, reforça sinergicamente um movimento de ações objetivas e subjetivas, que se ampliam para além de uma ação particular de uma esfera privada, em uma realidade local, o de "cada um fazer sua parte". Essa intencionalidade conectiva se propaga para além da comunicação direta do fato, mas também pela difusão imaterial e subjetiva dessa intencionalidade em um etéreo movimento consciente em uma "transição paradigmática"14, constituinte de um inconsciente coletivo, demarcados por um outro padrão relacional e civilizatório. É assumirmos em nossos "atos" 15 uma postura para fora, para a dimensão da esfera pública, superando uma forte tendência que o paradigma disjuntivo nos impõe de nos voltarmos para dentro da dimensão da esfera privada de vida.

\footnotetext{
${ }^{13}$ Para Espinosa, "a potência do meu ser se expressa através destas relações de proporção entre velocidade e repouso. Tal como a música, tal como a dança, a potência do ser é sua capacidade de gerar bons encontros e suportar maus encontros sem perder suas proporções. Somos corpos que vibram ao som da música divina." (https://razaoinadequada.com/2014/08/07/espinosa-a-potencia-do-ser/, consultado em 06/06/2019.

${ }^{14}$ Para Boaventura de Sousa Santos (2000) “... é simultaneamente um processo de superação e um processo de obsolescência. É superação na medida em que a modernidade cumpre alguma de suas promessas, em alguns casos até em excesso. É obsolescência na medida que a modernidade já não pode cumprir outras. Tanto o excesso como o déficit do cumprimento das promessas históricas explicam nossa presente situação, que aparece superficialmente como um período de crise, mas que, a um nível mais profundo, é um período de transição paradigmática." (Ibiden, 2000, p. 52)

${ }^{15}$ Para Espinosa, todo ato é potência. "Efetuar sua potência é necessariamente agir para gerar bons encontros, ou seja, compor com o mundo. Pense em um quarteto de cordas: eu tenho a capacidade de tocar violino, mas se estiver nervoso, eu posso tocar fora do tom e arruinar a música. Eu posso também tocar isolado de outros instrumentos, e neste caso nada aconteceria. Ou este ato de vibrar cordas do meu violino pode ser compor com a harmonia da música que está sendo tocada pelos meus companheiros. Neste caso, as cordas ressoam entre si, isto é o aumento da potência. Há ressonância. Eu atuo no mundo.”

(https://razaoinadequada.com/2014/08/07/espinosa-a-potencia-do-ser/, consultado em 06/06/2019.)
} 
Isso levaria a nos isolar do debate público e a não participar nos rumos da sociedade, reforçando uma posição disjuntiva ensimesmada. Ao nos encontrarmos na relação com o outro, posturas igualmente conectivas, buscando outros padrões relacionais, estaremos sinergicamente atuando em bons encontros nos movimentos contra-hegemônicos de transição paradigmática.

Enfrentar a crise socioambiental, nesta perspectiva de uma crise civilizatória, requer uma ruptura com modo de produção e consumo hegemônico e em seu modo de pensar e viver o mundo, o que nos impõe uma Educação Ambiental crítica, transformadora e emancipatória. Requer a afirmação de um outro modo de ser e estar no mundo, um modo dialógico, inclusivo e solidário. Não há uma rota de fuga para alguns, pois somos todos vulneráveis, juntos somos mais fortes na construção de novos caminhos. É, portanto, pela urgência e gravidade da crise que acreditamos importante a radicalidade da formação e atuação dos educadores ambientais. Um novo mundo urge, exige muitas Greta Thumberg no 1 com 1, eis o Educador Ambiental transformado e transformador!

\section{REFERÊNCIAS}

BAUMAN, Z. Modernidade Líquida. Rio de Janeiro: Jorge Zahar, 2001.

BONDÍA, J. L. Notas sobre a experiência e o saber de experiências. Revista Brasileira de Educação. n.19, 2002.

CARVALHO, I. Educação Ambiental: A Formação do Sujeito Ecológico. São Paulo: Cortez, 2004.

GARCÉS, M. Nueva ilustración radical. Barcelona: Anagrama, 2017.

GONZÁLEZ-GAUDIANO, E. Cambio Climático, una negación organizada. Ecopedagógica, 2 (3). 10-14, 2019.

GRAMSCI, A. Cadernos do Cárcere, 6 vols. Rio de Janeiro, Civilização Brasileira, 1999.

GUIMARÃES, M. Por uma educação ambiental crítica na sociedade atual. Revista Margens, p.1122, 2013.

HARARI, Y. N. Sapiens - Uma breve história da humanidade. $23^{\mathrm{a}}$ ed. Porto Alegre: L\&PM, 2017.

LATOUR, B. Dónde Aterrizar. Como orientarse em política. Madri: Taurus, 2019.

LAVAL, Ch. \& DARDOT, P. La nueva razón del mundo. Ensayo sobre la sociedad neoliberal. Barcelona: Gedisa, 2013.

LOVELOCK, J.E., MARGULIS, L. Atmospheric Homeostasis by and for the Biosphere: The Gaia hypothesis. Tellus, 1974.

LÖWY, M. As aventuras de Karl Marx contra o Barão de Münchhausen. Marxismo e positivismo na sociologia do conhecimento. 8.ed., São Paulo: Cortez, 2009. 
MEIRA, P. A. (Dir.); ARTO, M.; HERAS, F.; IGLESIAS, L.; LORENZO, J.J. \& MONTERO, P. La sociedad ante el cambio climático. Conocimientos, valoraciones y comportamientos en la población española. Madrid: Fundación MAPFRE, 2013.

MORIN, E. Ciência com Consciência. Rio de Janeiro: Bertrand Brasil, 1999.

SACHS, J., SCHMIDT-TRAUB, G., KROLL, C., LAFORTUNE, G., FULLER, G. SDG Index and Dashboards Report. New York: Bertelsmann Stiftung and Sustainable Development Solutions Network (SDSN), 2018.

SANTOS, B. de S. A Crítica da Razão Indolente. São Paulo: Cortez Editora, 2000.

THOMAS, W.I. A Metodologia do Estudo do Comportamento. Nova York: Alfred A. Knopf, 1928. 